Mehmet Akif Ersoy Üniversitesi Fen Bilimleri Enstitüsü Dergisi 11(1): 38-45 (2020)

The Journal of Graduate School of Natural and Applied Sciences of Mehmet Akif Ersoy University 11(1): $38-45$ (2020)

Araştırma Makalesi / Research Paper

\title{
Tasarıma Dayalı Eğitim Veren Bölümler İçin Sergi Alanı Önerisi: MAKÜ-MMF Örneği
}

\author{
Hüseyin Samet AŞIKKUTLU ${ }^{1}{ }^{1 *}$, Latif Gürkan KAYA ${ }^{(\mathbb{D} 1}$, Cengiz YÜCEDAĞ ${ }^{\mathbb{D} 1}$, Utku KURTOĞLUiD2 \\ ${ }^{1}$ Burdur Mehmet Akif Ersoy Üniversitesi, Mühendislik-Mimarlık Fakültesi, Burdur \\ ${ }^{2}$ KTO Karatay Üniversitesi, Konya \\ Geliş Tarihi (Received): 10.03.2020, Kabul Tarihi (Accepted): 08.04.2020 \\ $\square$ Sorumlu Yazar (Corresponding author $\left.{ }^{\star}\right)$ : sasikkutlu@mehmetakif.edu.tr \\ (C) +902482122790 圆 +902482132704
}

öz

Çalışmanın amacı, üniversitelerin tasarıma dayalı eğitim veren bölümlerinde öğrenim gören öğrencilerin jürilerinin yapılabileceği, sonrasında da bu proje ve maketlerin sergilenebileceği bir mekan düzenlemesi yapmaktır. Çalışmanın materyali, Burdur Mehmet Akif Ersoy Üniversitesi, Mühendislik-Mimarlık Fakültesi, Mimarlık ve Peyzaj Mimarlığı Bölümlerinin çizim atölyelerinin bulunduğu kattır. Çalışmada ilk olarak mekanın rölövesi çıkartılmış, AutoCAD programı kullanılarak sayısal plana aktarımış ve daha sonra bu mekan için yapılan tasarım SketchUp, V-Ray ve Adobe Photoshop programları kullanılarak 3 boyutlu olarak görselleştirilmiştir. Yapılan bu çalışmanın sonucunda, öğrencilerin proje jürilerinin yapılabileceği, ayrıca jürilerden sonra proje ve maketlerinin sergileneceği bir mekan önerilmiştir. Bu mekan önerisiyle sadece öğrencilerin derslere yönelik motivasyonlarında değil, aynı zamanda eğitim ve öğretimlerine dayalı başarıda da artış sağlanacaktır. Ayrıca, tüm yıl kullanılabilen daha yaşanabilir bir mekan oluşturmak ve mekandan tasarruf etmek mümkün olabilecektir.

Anahtar Kelimeler: MAKÜ, mekan, sergi, tasarım, üniversite

\section{Concept Exhibition Space for Departments with Design Education: Case Study of MAKU-MMF, Turkey}

\begin{abstract}
The aim of the study is to make a space arrangement where students exhibit their projects and models, and have their project juries at departments of universities with design education. The material of the study is the floor in which the drawing studios of the departments of Architecture and Landscape Architecture in the Faculty of Engineering and Architecture at the Burdur Mehmet Akif Ersoy University. In the study, first of all, the building survey of the place was first drawn, transferred to the digital plan using the AutoCAD program, and then the design made for this space was visualized in 3D using SketchUp, V-Ray and Adobe Photoshop programs. As a result of this study, a place where students' project juries can be performed and also their projects and models will be exhibited after the juries are proposed. With this space proposal, an increase not only in students' motivation for lessons, but also in their success based on their education and training will be achieved. In addition, it would be possible to create a more livable place that can be used all year and save space.
\end{abstract}

Keywords: MAKU, space, exhibition, design, university 


\section{Giriş}

Sergi kavramı, sahip olunan objeleri hem göstermek hem de ticari amaç doğrultusunda başka kişilere sunmak amacıyla oluşturulan bir düzenlemedir. Diğer taraftan, eski dilde kullanımıyla sergilemek olgusu teşhir etmek anlamına gelmektedir (Ayan Ergen, 2013). Insanoğlu geçmişten günümüze kadar saklamak, biriktirmek ve biriktirdiklerini de paylaşmak istemektedirler. Bu saklama ve biriktirme isteği sergileme anlayışının temelini oluşturmaktadır (Bayar, 2011).

Kavram olarak sergilemeyi, iletişim ile ilişkilendirmek mümkündür (Çetin, 2016). Başka bir deyişle, sergileme, sunma eylemi ile ilişkilendirilmektedir. Günümüzde görsel iletişim tasarımıyla sunma eyleminin birleştirilmiş haline sergileme tasarımı adı verilmektedir. Sergileme tasarımcıları ise görsel iletişim ve mesajı bütün olarak kullanıp elde edilen içeriği mekan aracılığıyla iletmektedirler. Dolayısıyla sergileme tasarımı, yerleşik çevre ve iletişim kavramını bir araya getirerek iletişim kuran mekanlar yaratmaktadır (Çalışkan, 2016).

Genellikle, sergiler mekanda tasarlanmaktadır. Mimari mekandaki, sergileme unsurlarının, istenilen gösterim sırasına ve ziyaretçinin algılama yeteneklerine uyan bir şemaya dahil edilmesi ve bütünleştirilmesi gerekmektedir. Dolayısıyla, kat planı organizasyonu kesintisiz bir sirkülasyonu sağlayarak ziyaretçileri hem teşvik etmeli hem de ziyaretçilerin tüm sergileri görmesini sağlamalıdır (Bayer, 1961).

Günümüze kadar, sergi alanları kavramını inceleyen birçok çalışma yapılmıştır. Örneğin; Güler (2009) çalışmasında, sergi alanlarında, sergi elemanlarının görsel temas ve inceleme sayısını artırmak için simülasyon uygulaması önermiştir ve çalışmasında simülasyon uygulamasıyla sergi tasarım hatalarının engellenebileceğini ifade etmiştir. Avcı (2010) çalışmasında, sergi salonlarında gün ışığından yararlanma durumunun mekan tasarımına etkisi konusunu incelemiştir ve sergileme mekanlarında doğru aydınlatma tekniklerinin kullanımının sergilemenin hedefine ulaşması açısından önemli olduğunu belirtmişlerdir. Lake-Hammond ve Waite (2010) çalışmalarında, sergi tasarımı kavramının değişen rolü ve bu konunun ziyaretçi merkezli müze ortamına etkisi konusunu incelemişlerdir. Tuğtağ (2018) çalışmasında, sergileme mekanlarının tasarımında yapının içeriğinin dikkate alınması gerektiğini ifade etmişlerdir. Çokyiğit ve ark. (2019) çalışmalarında, AVM'lerde sergileme elemanlarının tüketici davranışı üzerine etkisi konusunu incelemişlerdir ve mağaza tasarımlarında sergileme elemanlarına uygun bir yaklaşım benimsenmesi gerektiğini saptamışlardır.

Yukarıda bahsedilen bilgiler ışığında, sergi alanlarının tasarımlarına yönelik birçok soru akla gelmektedir ve bu sorulardan bazıları aşağıda belirtildiği şekilde olabilmektedir:

- Tasarıma dayalı eğitim veren bölümler için hem sınav dönemi hem de yıl içinde kullanım açısından sergi alanları neden düzenlenmiyor?

- Bu tür alanların tasarımlarıyla öğrencilerin motivasyonu ve eğitime yönelik başarılarında artış olabilir mi?

Belirtilen sorulara yanıt bulabilmek çalışmanın çıkış noktasını oluşturmaktadır. Bu bağlamda, çalışma kapsamında öncelikle sergi ve sergi alanlarıyla ilgili bilgi verilmiş, sonrasında arz-talep ilişkisi dikkate alınarak belirlenen bir mekanda sayısal ortamda tasarım yaklaşımının ne getireceği ortaya konulmuştur.

Üniversitelerde tasarıma dayalı eğitim veren bölümler hem sınav dönemleri hem de yıl içinde kullanım açısından sergi alanlarına gereksinim duymaktadırlar. Bu alanlarda öğrenci projeleri ve maketleri ya da farklı proje örneklerinin sergilenmesinin öğrencilerin bilgi birikimine katkı sağlayacağı ve mesleki anlamda kendilerini geliştirmelerine etkili olacağı ifade edilebilir. Bu nedenle bu çalışmada, materyal olarak belirlenen Burdur Mehmet Akif Ersoy Üniversitesi (MAKÜ), Mühendislik-Mimarlık Fakültesi (MMF), Mimarlık ve Peyzaj Mimarlığı Bölümlerinin çizim atölyelerinin bulunduğu katta bir sergi alanı düzenlenmesi amaçlanmıştır.

\section{MATERYAL VE YÖNTEM}

Çalışmanın ana materyali, Burdur Mehmet Akif Ersoy Üniversitesi, Mühendislik Mimarlık Fakültesi, Mimarlık ve Peyzaj Mimarlığı Bölümlerinin çizim atölyelerinin bulunduğu kattır. Şekil 1'de çalışma alanının konumu verilmiştir. 


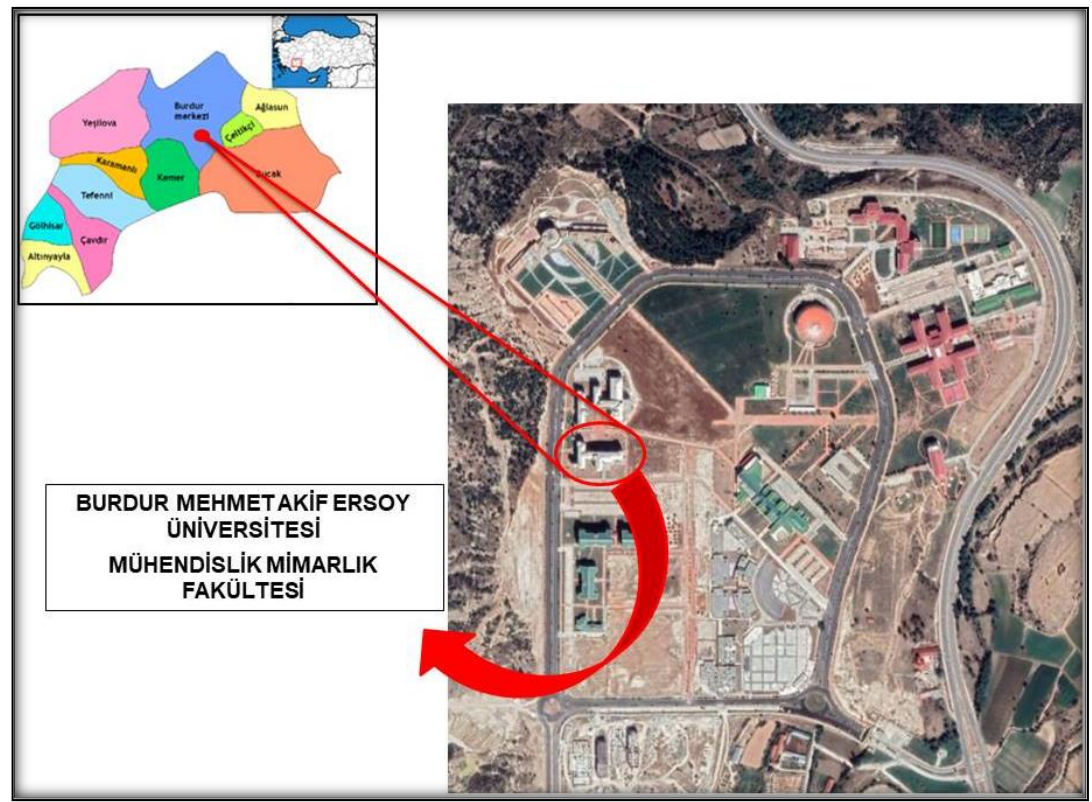

Şekil 1. Çalışma alanının konumu (URL-1, 2019)

Şekil 2' de MAKÜ Mühendislik Mimarlık Fakültesi, Mimarlık ve Peyzaj Mimarlığı Bölümlerinin çizim atölyelerinin bulunduğu kattaki derslik koridorunun mevcut durumunu gösteren görünümler sunulmuştur.
Şekil 3'de, MAKÜ Mühendislik Mimarlık Fakültesi kat planı sunulmuştur.

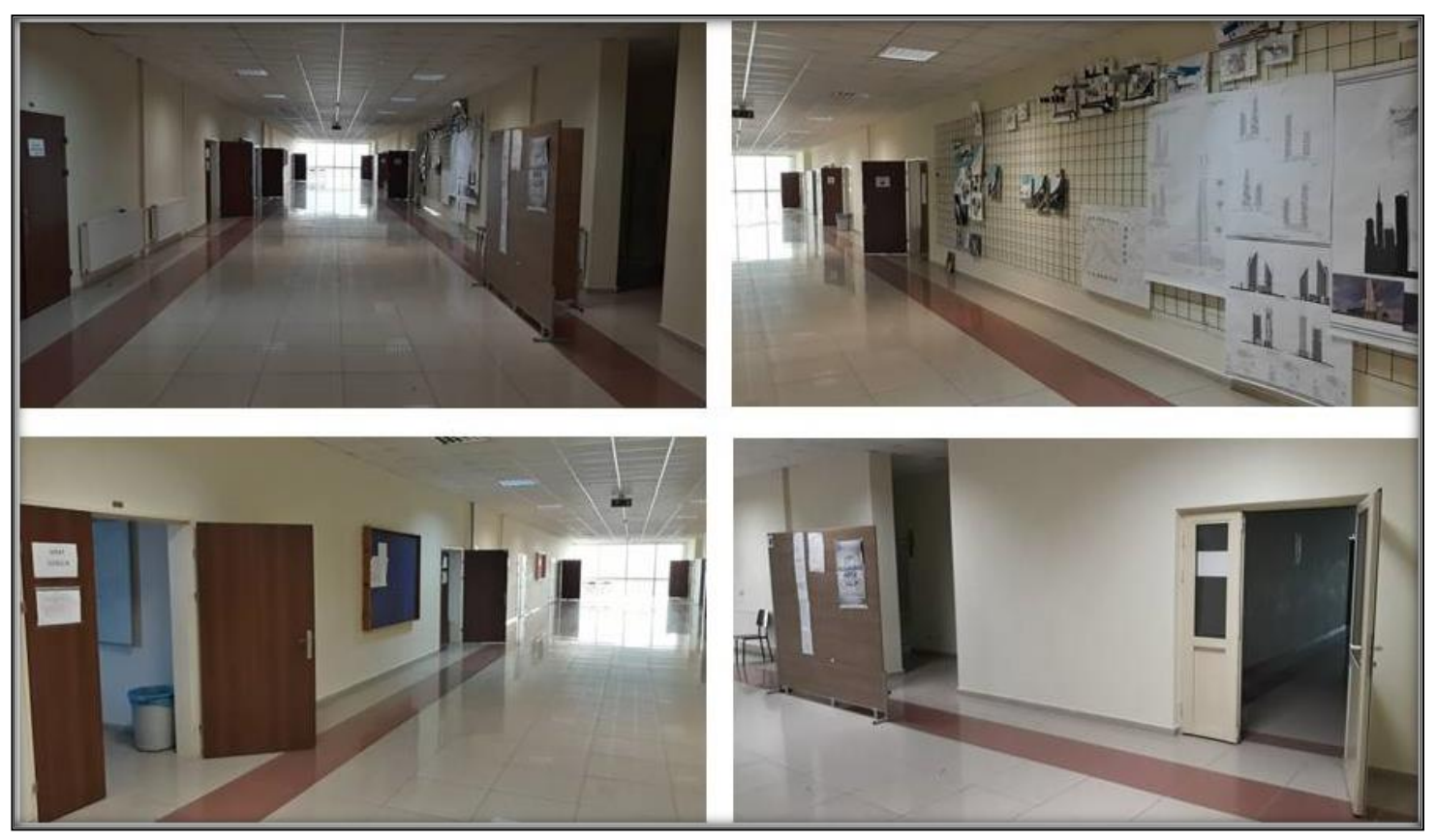

Şekil 2. MAKÜ-MMF derslik koridorundan görünümler 


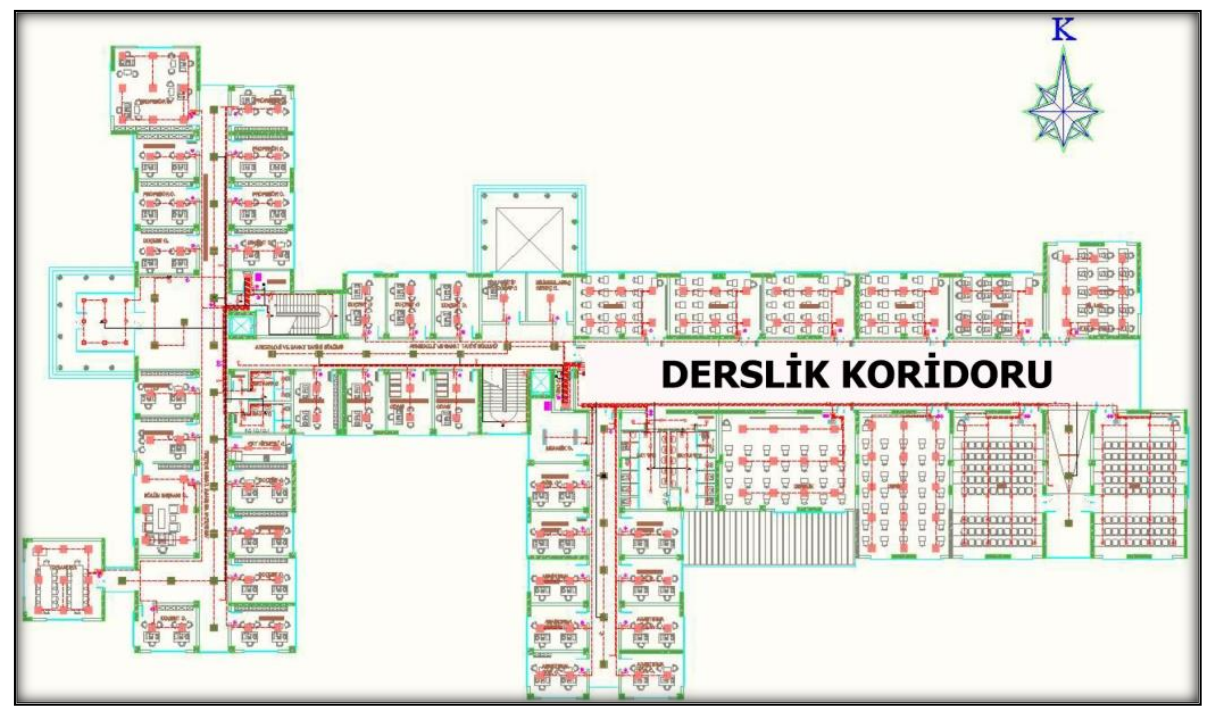

Şekil 3. MAKÜ-MMF kat planı (Kırbaş, 2019)

Burdur Mehmet Akif Ersoy Üniversitesi Mühendislik Mimarlık Fakültesi 4 Temmuz 2011 tarih ve 27984 (2. Mükerrer) sayılı Resmi Gazetede yayımlanan Bakanlar Kurulu kararı ile kurulmuştur ve halen MAKÜ İstiklal Yerleşkesi Fen Edebiyat Fakültesi B Blok içerisinde bulunmaktadır (URL-2, 2019).

Bu çalışma 2019 yılı Mart ve Mayıs aylarında gerçekleştirilmiştir. Çalışma alanı ile ilişkili ölçüm ve gözlemler yapılarak mevcut durum analiz edilmiştir. Tasarıma yönelik eskiz çalışmaları yapılmış ve bu doğrultuda kullanılacak malzemeler belirlenmiştir. Çalışmada yöntem olarak AutoCAD, SketchUp, V-Ray ve Adobe Photoshop programları kullanılmış ve bu programlar ile sergi alanı görsel nitelikte modellenmiştir. Çalışmanın hazırlanmasında izlenen aşamalar yöntem akış şemasında sunulmuştur (Şekil 4).

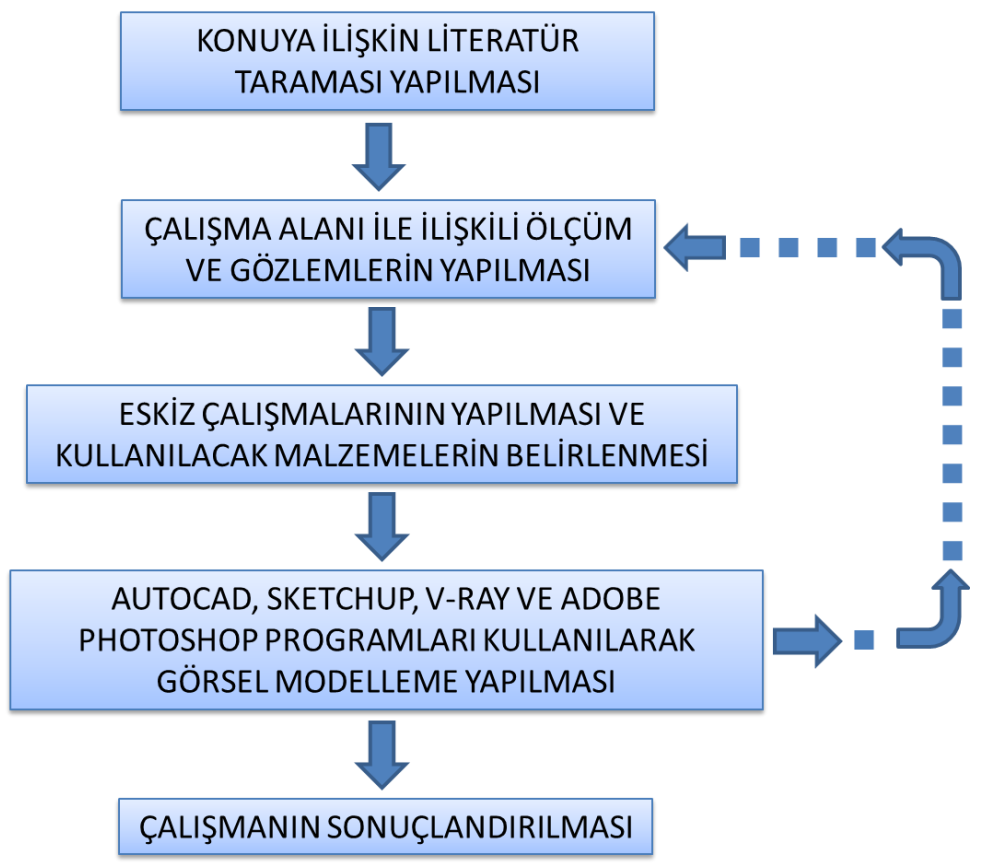

Şekil 4. Yöntem akış şeması 


\section{BULGULAR VE TARTIŞMA}

Öğrencilerin yapmış oldukları proje çalışmalarının jüri esnasında değerlendirilebilmesi ve sonrasında sergilenebilmesi için duvar yüzeyinde çelik hasır sergi panolarının kullanımı önerilmiştir (Şekil 5).
Ayrıca, tasarımda altı adet taşınabilir pano kullanıımıştır. Panoların mekan içinde farklı bölgelere taşınması ile jüri ve sergi esnasında ziyaretçi sirkülasyonu bağlamında oluşabilecek sorunların giderilmesi ve sergi alanında artışın sağlanması amaçlanmıştır (Şekil 6).

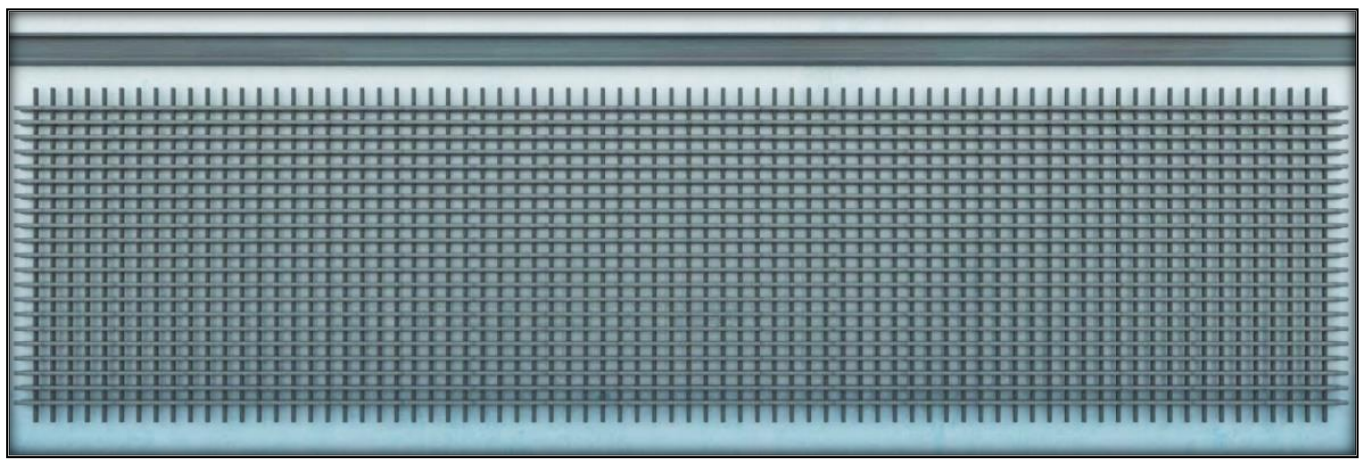

Şekil 5. Duvar yüzeyine ilişkin öneri çelik hasır sergi panosu tasarımı

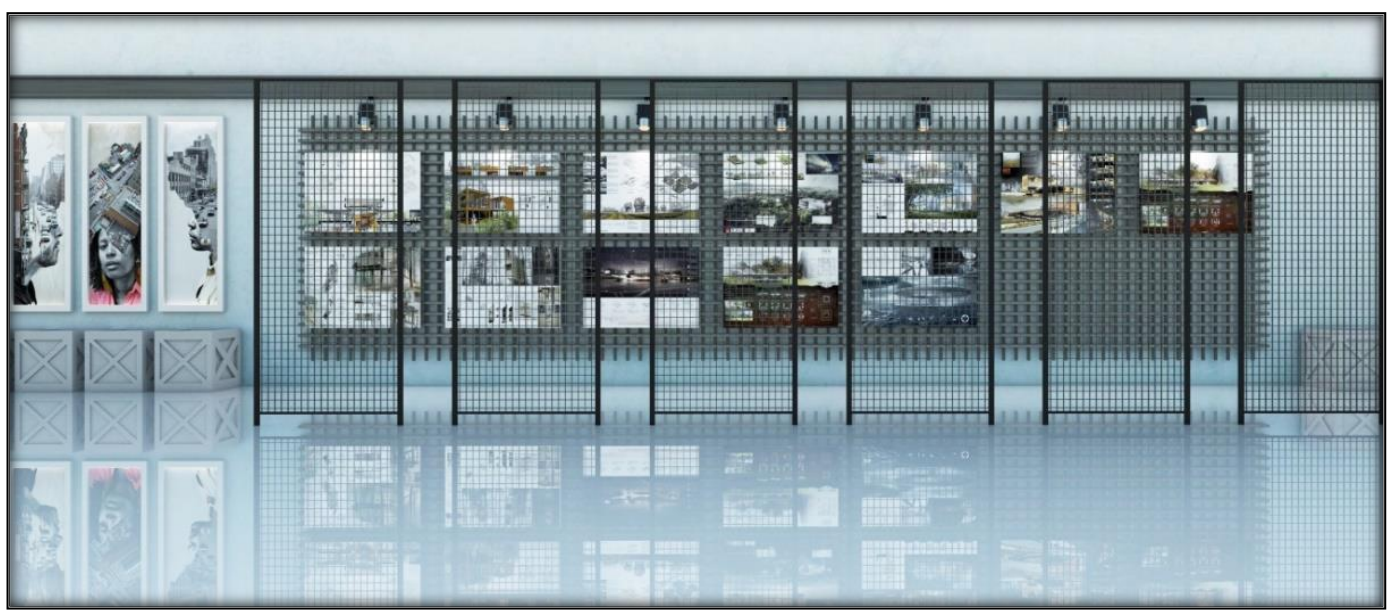

Şekil 6. Taşınabilir panolara ilişkin öneri tasarım

Mekan içerisindeki algıyı iyileştirmek için panoda raylı spotlar kullanılmıştır. Kullanılan aydınlatma elemanlarıyla, panolarda sergilenen çalışmanın ön plana çıkması amaçlanmıştır (Şekil 7). Konuyla ilgili olarak; Kırbaş (2019), MAKÜ Mühendislik Mimarlık Fakültesi binasının aydınlatılması kapsamında enerji tasarrufuna yönelik bazı önerilerde bulunmuştur.
Mekanın hem daha geniş algılanması hem de ziyaretçilerin daha rahat bir şekilde mekanda dolaşmaları amacıyla derslik girişlerinde sürgülü kapılar kullanılmıştır. Ayrıca bu sürgülü kapılarda ahşap malzeme kullanılarak doğal ve estetik bir etki oluşturulması hedeflenmiştir (Şekil 8). 


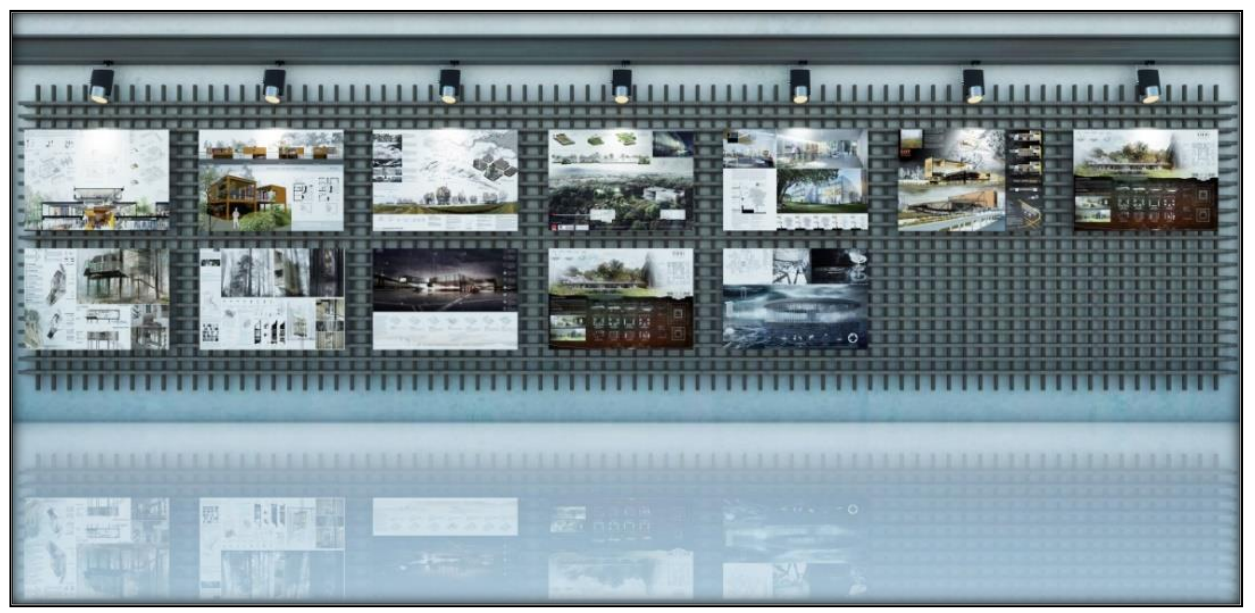

Şekil 7. Sergi alanında aydınlatma elemanları ve panolara ilişkin öneri tasarım

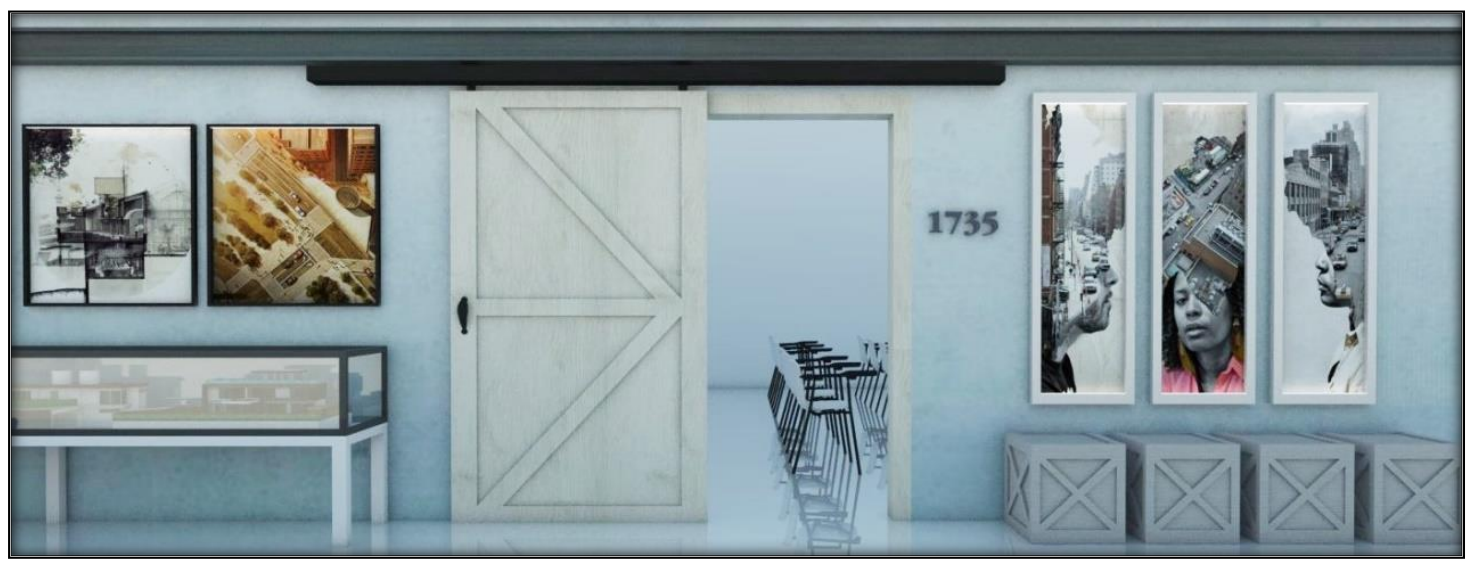

Şekil 8. Sergi alanına açılan derslik kapılarına ilişkin öneri tasarım

Mekanda ziyaretçilerin dinlenebilmeleri için ahşap oturma birimleri oluşturulmuştur (Şekil 9).

Öğrencilerin projeleri kapsamında yaptıkları maketler ya da farklı maket örneklerini tanıtmak amacıyla cam kapaklı sergileme birimleri oluşturulmuştur. Ayrıca, sergi alanında kullanılan ışıklandırmalı ahşap raflar sayesinde öğrencilerin intiyaç duydukları bazı yayınlara ulaşmaları hedeflenmiştir. Diğer taraftan, bu mekan oturma birimleriyle desteklenmiştir (Şekil 10).

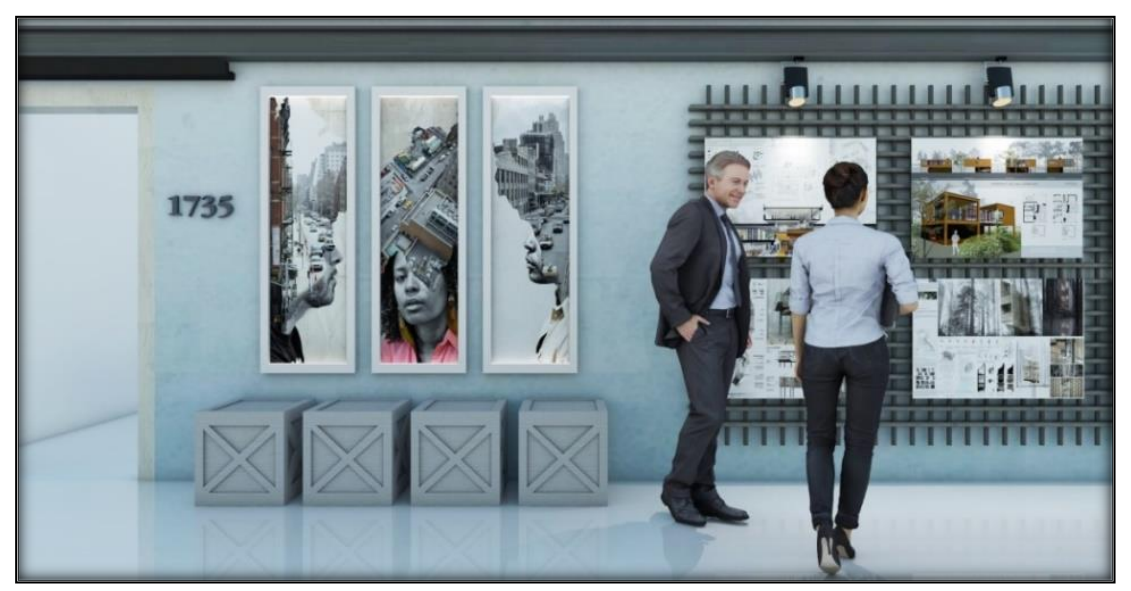

Şekil 9. Ahşap oturma birimlerine ilişkin öneri tasarım 


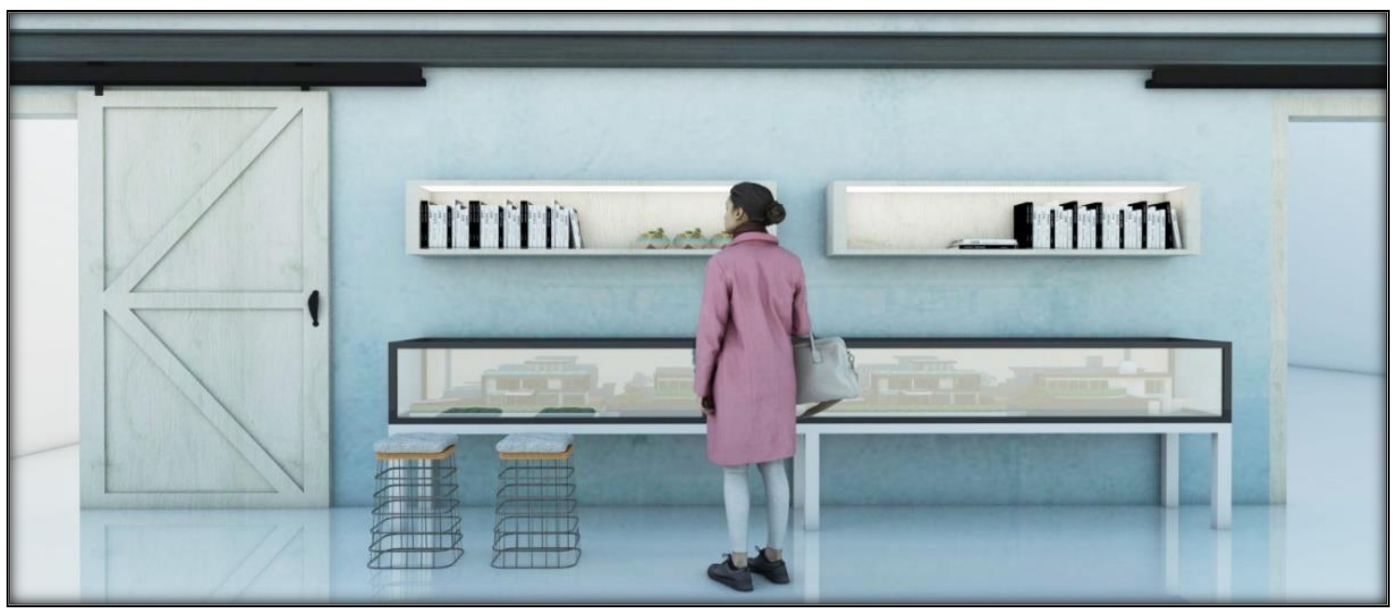

Şekil 10. Sergi alanında kullanılan cam kapaklı sergileme birimi, ı̧ıkı ahşap kitaplık ve oturma birimlerine ilişkin öneri tasarım

Hem sınav haricinde kullanım için hem de stüdyo sınavlarında jüri üyelerinin projeleri değerlendirmeleri ve dinlenebilmeleri amacı ile koridorun sonunda büyük pencerelerin olduğu ve iç mekan bitkilerinin kullanıldığı bir oturma alanı oluşturulmuştur. Ayrıca bu mekan sergi alanından göz hizası seviyesinde ahşap paravan ile ayrılmıştır (Şekil 11).

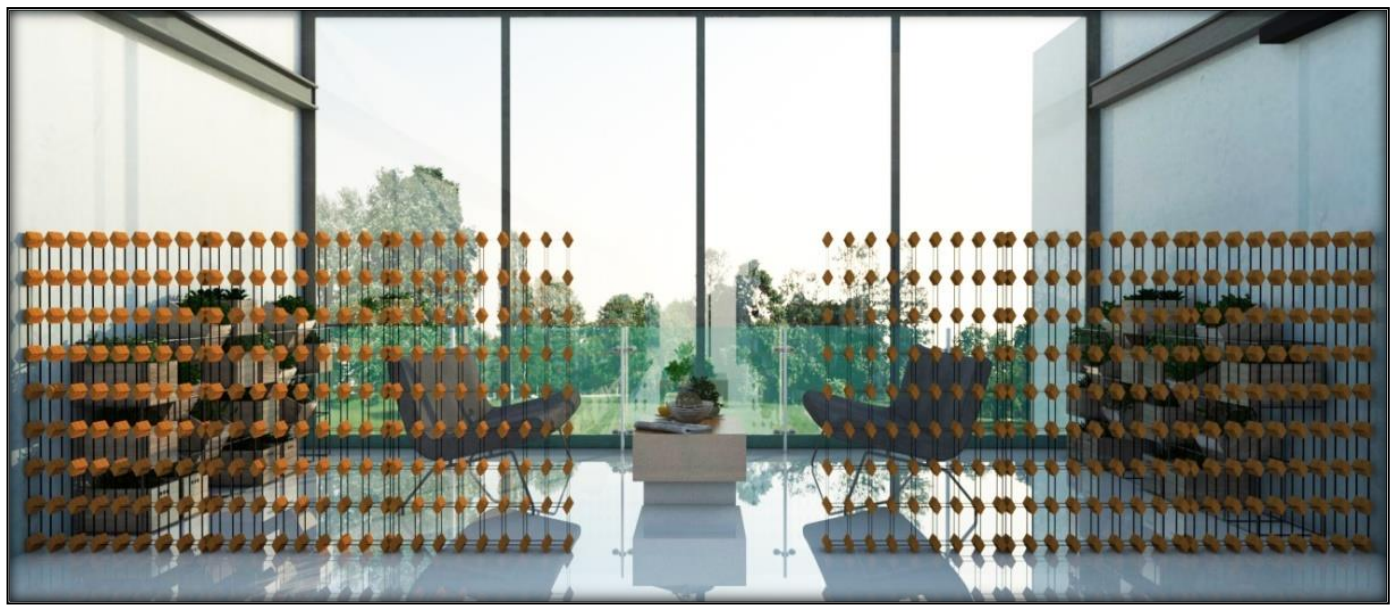

Şekil 11. Oturma alanına ilişkin öneri tasarım

\section{SONUÇ VE ÖNERILER}

Çalışma kapsamında, tasarıma dayalı eğitim alan öğrencilerin jürilerinin yapılabileceği, ayrıca jürilerden sonra proje ve maketlerinin sergileneceği bir mekan düzenlemesi yapılmıştır. Sonuçta;

- Bu tür mekanlarda yapılacak düzenleme çalışmalarıyla öğrencilerin derslere yönelik motivasyonlarının artması yanında eğitim ve öğretimlerine dayalı başarılarında artış görülebilecektir.

- Eğitim kurumlarının iç mekanlarında daha yaşanabilir mekanlar oluşturmak mümkün olabilecektir.

- Yapı içinde; sergi alanı, sınav salonu ya da derslik gibi birçok işlevi aynı anda kullanarak mekandan tasarruf etmek sağlanabilecektir.

- Eğitim-öğretim yılı süresince kullanılacak bir mekan elde etmek mümkün olabilecektir.

\section{KAYNAKLAR}

Avcı, C. (2010). Sergi salonlarında gün ışığından yararlanma ve mekân tasarımına etkisi. Mimar Sinan Güzel Sanatlar Üniversitesi, Fen Bilimleri Enstitüsü, İç Mimarlık Anasanat Dalı, Yüksek Lisans Tezi, İstanbul, Türkiye, s: 92.

Ayan Ergen, B. (2013). Sanat yapıtı sergileme ve sunum çeşitlerine örnekler eşliğinde bir bakış. Akdeniz Sanat Dergisi. 6 (11): 130-143.

Bayar, Z. (2011). Sergileme tasarımında yeni yaklaşımlar ve bir proje önerisi. Dokuz Eylül Üniversitesi, Güzel Sanatlar 
Enstitüsü, Grafik Anasanat Dalı, Yüksek Lisans Tezi, İzmir, Türkiye, s: 126.

Bayer, H. (1961). Aspects of design of exhibitions and museums. CURATOR. 4 (3): 257-288.

Çalışkan, C. (2016). Sergileme tasarımının gelişimi ve müze ile sanat galerilerinin karşılaştırılması. Yıldız Journal of Art and Design. 3 (1): 26-42.

Çetin, İ. (2016). Sergi mekânlarına dönüştürülen, işlevini yitirmiş olan yapıların çağdaş sergileme anlayışı kapsamında irdelenmesi. Hacettepe Üniversitesi, Güzel Sanatlar Enstitüsü, İç Mimarlık ve Çevre Tasarımı Anabilim Dalı, Yüksek Lisans Tezi, Ankara, Türkiye, s: 172.

Çokyiğit, H., Kaya, L. G., Yücedağ, C., Aşıkkutlu, H. S. (2019). AVMlerde sergileme elemanlarının tüketici davranışına etkisi: Antalya örneği. İçinde: Mimarlık Planlama ve Tasarım Alanında Araştırma ve Değerlendirmeler. Kaya, L. G. (eds.), Gece Kitaplığı, Ankara, Türkiye, 193-207.
Güler, Ö. K. (2009). Sergi mekanlarında ziyaretçi dolaşımı için bir simulasyon uygulaması. İhsan Doğramacı Bilkent Üniversitesi, Güzel Sanatlar Enstitüsü, İç Mimarlık ve Çevre Tasarımı Anasanat Dalı, Yüksek Lisans Tezi, Ankara, Türkiye, s: 87.

Kırbaş, ì. (2019). Binalarda enerji verimliliği uygulamaları: MAKÜ Mühendislik Mimarlık Fakültesi örneği. Mehmet Akif Ersoy Üniversitesi Fen Bilimleri Enstitüsü Dergisi. 10 (2): 141-149.

Lake-Hammond, A., Waite, N. (2010). Exhibition design: bridging the knowledge gap. The Design Journal. 13 (1): 7798.

Tuğtağ, M. (2018). Sergilemede mekân tasarımları. Aydın Sanat. 4 (8): 107-117.

URL-1 (2019). Burdur harita. https://www.turkcebilgi.com/burdur_(il) (Erişim tarihi: 27/11/2019).

URL-2 (2019). Mühendislik Mimarlık Fakültesi. https://mmf.mehmetakif.edu.tr/icerik/265/463/genel-bilgi (Erişim tarihi: 27/11/2019). 